Self-determination, loneliness, fear of missing out, and academic performance

David John Lemay

McGill University, Montreal, QC, Canada

Tenzin Doleck

University of Southern California, CA, USA

Paul Bazelais

McGill University, Montreal, QC, Canada

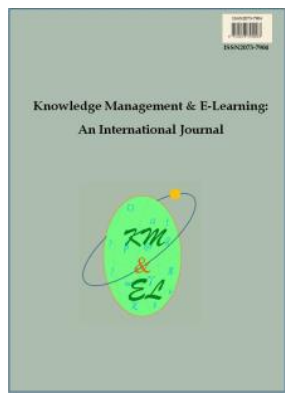

Knowledge Management \& E-Learning: An International Journal (KM\&EL) ISSN 2073-7904

Recommended citation:

Lemay, D. J., Doleck, T., \& Bazelais, P. (2019). Self-determination, loneliness, fear of missing out, and academic performance. Knowledge Management \& E-Learning, 11(4), 485-496. https://doi.org/10.34105/j.kmel.2019.11.025 


\title{
Self-determination, loneliness, fear of missing out, and academic performance
}

\section{David John Lemay}

McGill University, Montreal, QC, Canada

E-mail: david.lemay@mail.mcgill.ca

\section{Tenzin Doleck*}

University of Southern California, CA, USA

E-mail:doleck@usc.edu

\section{Paul Bazelais}

McGill University, Montreal, QC, Canada

E-mail: paul.bazelais@mail.mcgill.ca

*Corresponding author

\begin{abstract}
Instances of anxiety, depression, and loneliness are attaining epidemic-levels among college-age students. Self-determination theory suggests that such feelings are attributable to antagonistic situations hindering the satisfaction of an individual's basic needs for autonomy, competence, and relatedness. Fear of Missing Out (FOMO) is a phenomenon that arose in the context of social media use and refers to the need to stay continually connected. Studies have shown that problematic social media and mobile technology use are related to feelings of anxiety, depression, and loneliness, and FOMO. Few studies have examined the relationships between these factors and academic performance. This study examines how Loneliness, FOMO, and the basic needs Autonomy, Competence, and Relatedness, are related to Academic Performance. We find a positive influence of FOMO and a negative influence of Autonomy on Academic Performance. We discuss these and other findings.
\end{abstract}

Keywords: Loneliness; Fear of missing out; Academic achievement; Selfdetermination theory; College students

Biographical notes: David John Lemay is a research associate with the Faculty of Medicine, McGill University, QC.

Tenzin Doleck is a Provost's Postdoc Fellow at the University of Southern California, USA.

Paul Bazelais is a doctoral student at McGill University and an instructor at John Abbott College in Montreal, QC. 


\section{Introduction}

In our hyper-connected world, it should be surprising that people are suffering from epidemic levels of loneliness (Mahoney et al., 2019; McPherson, Smith-Lovin, \& Brashears, 2006). But the advent of social media has been having adverse effects on populations around the globe (Ahn, 2011; Elhai, Dvorak, Levine, \& Hall, 2017; Elhai, Levine, Dvorak, \& Hall, 2017; Goodman-Deane et al., 2016; Pittman \& Reich, 2016; Turkle, 2011). Although it has demonstrated the ability to empower social movements and spread revolution (Eltantawy \& Wiest, 2011; Lim, 2012), paradoxically, new information technologies have also led to increased disconnection and increased feelings of loneliness. To respond to this public crisis of mental health, we need to better understand the effects on individuals and communities, both online and offline.

For many, especially the generation growing up with social media and mobile technology, being always connected and accessible means growing up in the public eye. Bullying now takes on massive proportions magnified by social media technologies. And constant access and endless scrolling appear to induce anxiety and distractedness (Elhai, Dvorak, Levine, \& Hall, 2017; Oberst et al., 2017; Wegmann et al., 2017), or the Fear of Missing Out (FOMO; Przybylski et al., 2013), from the need to constantly stay on top of the news, or their social feed, knowing full well the futility of the act or the impossibility of ever getting to the end of the internet. Comorbid factors depression, loneliness, life satisfaction, anxiety have all been related to differences in SNS usage (Sheldon \& Bryant, 2016; Krasnova et al., 2015). Personality differences also influence our perceptions and use of information technologies (Barnett, Pearson, Pearson, and Kellermanns, 2015), for instance, neuroticism is linked to anxiety and depression and shows different patterns of technology usage.

At present, it remains unclear to what extent these are due to social factors or individual differences, such as a person's internal motivations or basic needs (Deci \& Ryan, 1985; Ryan \& Deci, 2000). Differences may influence an individual's experience of loneliness or FOMO. For example, an individual with a higher perceived need for relatedness may report higher levels of loneliness or FOMO compared to an individual with a greater perceived need for personal autonomy. Moreover, there is scant literature on the relationship between individual differences, FOMO, and loneliness in the academic context (Alt, 2015). Different motivational profiles and self-perceptions influence academic performance as sense of relatedness mediated by engagement and disaffection has been shown to influence academic achievement (Taylor et al., 2014; King, 2015). The present study seeks to understand how an individual's needs for selfdetermination are related to feelings of loneliness and FOMO and college students' academic performance.

\section{Literature review}

\subsection{Fear of missing out and loneliness}

Fear of Missing Out arose in the context of social media use. "Defined as a pervasive apprehension that others might be having rewarding experiences from which one is absent, FoMO is characterized by the desire to stay continually connected with what others are doing. For those who fear missing out, participation in social media may be especially attractive." (Przybylski et al., 2013, p.1841). Whereas Alt (2015) found that FOMO influenced social media engagement and that extrinsic and amotivation profiles 
influenced FOMO but not intrinsic motivation, FOMO and problematic internet use are related to lower levels of subjective well-being (Stead \& Bibby, 2017). Błachnio and Przepiórka (2018) reproduced the FOMO and problematic internet use link and also found that narcissism predicts life satisfaction though not FOMO. In a study of adolescents' sleep patterns, Scott and Woods (2018) found that FOMO predicted shorter sleep duration. Neuroticism and extraversion have been linked to social media use and appear to overlap with FOMO in the case of social media addiction (Blackwell et al., 2017).

In a systematic review of problematic smartphone use and relationships to psychopathologies, Elhai, Dvorak, Levine, and Hall (2017) found that severity of anxiety and depression consistently predicted problematic uses, stress and self-esteem were less consistently related. However, most effects were small to moderate. As the authors discuss, there are possibly other explanatory factors involved. Anxiety, depression, stress, and self-esteem may be seen as comorbid conditions and may be results rather than causes themselves. Relational theories such as self-determination theory (Ryan \& Deci, 2000) place the individual within the social group and understand individual motivations as relating to basic needs satisfactions. Indeed, many studies (Oberst et al., 2017; Wegmann et al., 2017) have concluded that FOMO, as a need, mediated the relationship between anxiety and depression psychopathologies and problematic social media use. Moreover, Przybylski et al. (2013) found that FOMO was related to lower mood, life, and needs satisfaction, and that FOMO mediated the link between these individual differences and social media engagement. It appears that FOMO may be influenced by an individual's motivational profile, in terms of basic needs satisfaction, and hence may also influence individuals' academic performance.

\subsection{Self-determination theory}

Self-Determination Theory (SDT; Deci \& Ryan, 1985; Ryan \& Deci, 2000; Vallerand, Fortier, \& Guay, 1997) is a motivational theory that is based in relational perspective. It explains individual goal-directed, or agentic, behavior as motivated by the satisfaction of three overriding needs of the individual with respect to others, that is, the need for autonomy, competence and relatedness. SDT stipulates two main evolved propensities for action, that is, intrinsic and extrinsic motivation, or internal and external sources of motivation, and the authors imagine a continuum between the two. On the one end, intrinsic "natural inclination toward assimilation, mastery, spontaneous interest, and exploration that is so essential to cognitive and social development and that represents a principal source of enjoyment and vitality throughout life" (Ryan \& Deci, 2000). On the other, extrinsic motivation runs the gamut from internalizing and self-identifying strategies to externally motivating or amotivational forms. SDT is composed of two related sub-theories (Deci \& Ryan, 1985; Ryan \& Deci, 2000): cognitive evaluation theory argues that intrinsic motivation can be afforded or constrained to the degree that the social-context environment is supportive of autonomy and competence; while organismic integration theory stipulates that the integration of extrinsic sources of motivation will be most successful where relatedness or connection is afforded in the social environment.

An individual's needs for competence, autonomy, and relatedness are likely to be direct predictors of feelings of loneliness or FOMO. Given the wide body of literature on motivation and academic performance, it appears clear that motivation influences academic performance, and we can expect that all these constructs are highly interrelated (Taylor et al., 2014; Vansteenkiste et al., 2009). A better understanding of these links can 
help develop better social media habits and to adopt more adaptive strategies for coping with anxiety, depression, and loneliness in college students.

\section{Research question}

Thus, our research question was: "How do Self-Determination Variables Need for Autonomy, Competence, and Relatedness and Loneliness and Fear of Missing Out relate to Academic Performance?" Fig. 1 shows the path relationships we tested in our research model.

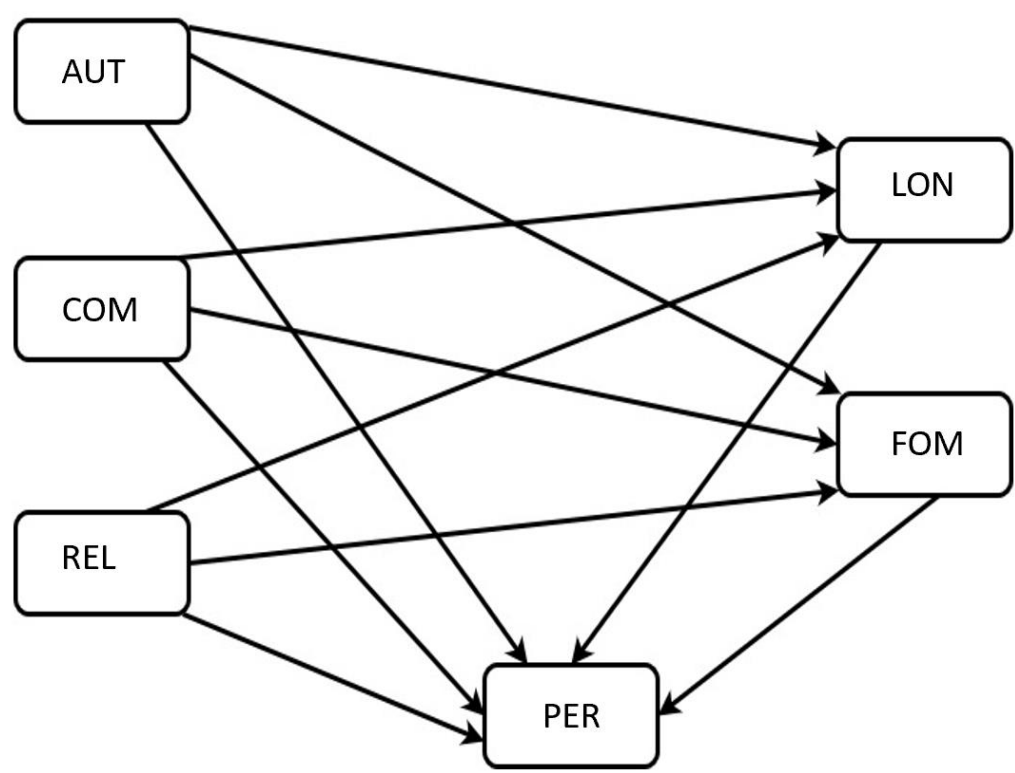

Fig. 1. Proposed research model

As SDT posits that basic needs satisfaction supports intrinsic motivation and intrinsic motivation supports academic achievement (Taylor et al., 2014), we hypothesized that individuals' perceived need for Competence and Relatedness in college would be positively linked to academic achievement, whereas as Autonomy would be negatively related as students high in Autonomy in college are likely prone to be motivated by idiosyncratic learning goals not oriented towards performance or academic achievement. This leads to the following hypotheses:

H1. Need for Competence (COM) is positively linked to academic achievement (PER)

H2. Relatedness (REL) is positively linked to academic achievement (PER)

H3. Autonomy (AUT) is negatively linked to academic achievement (PER)

In SDT, Loneliness and FOMO can be considered environmental dysregulations and hence, individuals high in either are likely to be more driven by extrinsic motivation, and more driven to performance, thus we would expect a positive relationship between Loneliness, FOMO, and Academic Achievement.

H4. Loneliness (LON) is positively linked to academic achievement (PER)

H5. FOMO (FOM) is positively linked to academic achievement (PER) 
We expected no significant relationships between perceived Autonomy and Competence and both Loneliness and FOMO in college as the latter speak of a deep need of relatedness. Thus, we expected positive relationships between need for Relatedness and Loneliness, and FOMO.

H6. Autonomy (AUT) is not related to Loneliness (LON)

H7. Autonomy (AUT) is not related to FOMO (FOM)

H8. Competence (COM) is not related to Loneliness (LON)

H9. Competence (COM) is not related to FOMO (FOM)

H10. Relatedness (REL) is positively linked to Loneliness (LON)

H11. Relatedness (REL) is positively linked to FOMO (FOM)

\section{Methodology}

\subsection{Participants and procedure}

A sample of 102 students from a pre-university program at an English Collège d'enseignement général et professionnel (CEGEP; Bazelais, Lemay, \& Doleck, 2016; Bazelais, Lemay, \& Doleck, 2019) participated in the study. Among the 102 students, 53 were female, 48 were males, and 1 was asexual. Participants had a mean age of 18.17 $(S D=0.90)$. Participants were asked to complete a questionnaire which included items related to the constructs in the research model. Participation was voluntary and students were assured that their responses would remain anonymous and confidential. We follow sample size requirements discussed in Wolf et al. (2013) Monte Carlo study of sample size and SEM, arguing smaller models can be tested with smaller samples than the rule of 10 per item.

\subsection{Measures}

We used the autonomy, competence, and relatedness scales (Jenkins-Guarnieri, Vaughan, \& Wright, 2015) to assess students' self-determination needs; students responded on a 5point Likert scale ( $1=$ Not at all true; 5=Very true). The loneliness scale (Russell, Peplau, \& Cutrona, 1980) was used to evaluate students' level of loneliness; students responded using a 4-point Likert scale (1=I often feel this way; 4=I never feel this way). The FOMO scale (Przybylski, Murayama, DeHaan \& Gladwell, 2013; Bosau \& Aelker, 2015) was used to assess students' FOMO level; students rated a 5-point Likert scale (1=Not at all true of me; 5=Extremely true of me). For academic performance, students reported their overall $R$-Score; in Quebec, the $R$-score is used as an indicator of students' academic performance (Bazelais, Doleck, \& Lemay, 2017; Bazelais, Lemay, \& Doleck, 2018; CREPUQ, 2007). Participants also provided demographic information. It should be noted that these instruments are perceptual self-report measures that are intended as measures of an individual's state at a specific time point and context as opposed as measures of more durable long-term individual traits. 


\section{Data analysis and findings}

We used partial least squares (PLS; Henseler, Hubona, \& Ray, 2016) approach to test the associations between the constructs. In the present study, all analyses were carried out using the WarpPLS tool (Kock, 2015a, 2015b). We followed the standard two-step modeling process: measurement model and structural model (Kock, 2015b).

\subsection{Measurement model}

As seen in Table 1, the data fit the model well (Kock, 2015b). The psychometric properties of the measurement model were assessed using the guidelines suggested by Kock (2015b). The factor loadings which exceeded 0.70 are presented in Table 2. Furthermore, in Table 3, the composite reliability coefficients of the measures all exceeded the threshold value of 0.70 . Thus, the reliability of the indicators was established. Composite convergent validity was assessed through the average variance extracted (AVE) test on the variables, where all AVEs exceeded the recommended threshold value of 0.50 .

Table 1

Model fit statistics

\begin{tabular}{lll}
\hline Measure & Values & Recommended Criterion \\
\hline Average path coefficient (APC) & $0.189, P=0.012$ & Acceptable if $P<0.05$ \\
Average R-squared (ARS) & $0.230, P=0.004$ & Acceptable if $P<0.05$ \\
Average adjusted R-squared (AARS) & $0.200, P=0.009$ & Acceptable if $P<0.05$ \\
Average block VIF (AVIF) & 1.145 & Acceptable if $<=5$ \\
Average full collinearity VIF (AFVIF) & 1.362 & Acceptable if $<=5$ \\
\hline
\end{tabular}

Table 2

Loadings of measurement items

\begin{tabular}{llllllll}
\hline & AUT & COM & REL & LON & FOM & PER & P value \\
\hline AUT2 & $\mathbf{0 . 6 4 3}$ & -0.132 & 0.223 & -0.056 & -0.120 & 0.073 & $<0.001$ \\
AUT3 & $\mathbf{0 . 8 3 5}$ & -0.023 & 0.065 & -0.103 & -0.022 & 0.069 & $<0.001$ \\
AUT4 & $\mathbf{0 . 8 1 5}$ & 0.128 & -0.243 & 0.150 & 0.117 & -0.128 & $<0.001$ \\
COM3 & 0.111 & $\mathbf{0 . 8 6 5}$ & -0.040 & 0.112 & 0.094 & -0.098 & $<0.001$ \\
COM4 & -0.111 & $\mathbf{0 . 8 6 5}$ & 0.040 & -0.112 & -0.094 & 0.098 & $<0.001$ \\
REL1 & -0.042 & 0.132 & $\mathbf{0 . 8 6 7}$ & -0.107 & -0.049 & -0.034 & $<0.001$ \\
REL2 & -0.025 & 0.026 & $\mathbf{0 . 7 9 5}$ & -0.030 & -0.115 & 0.028 & $<0.001$ \\
REL3 & 0.067 & -0.160 & $\mathbf{0 . 8 4 4}$ & 0.139 & 0.159 & 0.008 & $<0.001$ \\
LON2 & 0.012 & 0.082 & 0.049 & $\mathbf{0 . 8 7 6}$ & 0.204 & -0.129 & $<0.001$ \\
LON4 & -0.012 & -0.082 & -0.049 & $\mathbf{0 . 8 7 6}$ & -0.204 & 0.129 & $<0.001$ \\
FOM1 & -0.038 & 0.101 & -0.034 & -0.153 & $\mathbf{0 . 7 6 2}$ & -0.105 & $<0.001$ \\
FOM2 & -0.059 & 0.073 & -0.019 & -0.099 & $\mathbf{0 . 9 1 2}$ & -0.041 & $<0.001$ \\
FOM3 & -0.015 & -0.086 & 0.020 & 0.112 & $\mathbf{0 . 8 3 1}$ & 0.133 & $<0.001$ \\
FOM4 & 0.129 & -0.097 & 0.036 & 0.155 & $\mathbf{0 . 7 3 6}$ & 0.010 & $<0.001$ \\
PER1 & -0.000 & -0.000 & 0.000 & 0.000 & -0.000 & 1.000 & $<0.001$ \\
\hline
\end{tabular}

Note. Loadings in bold 
Table 3

Measurement scale characteristics

\begin{tabular}{lcc}
\hline Construct & Composite reliability (CR) coefficients & Average variance extracted (AVE) \\
\hline AUT & 0.811 & 0.592 \\
COM & 0.856 & 0.748 \\
REL & 0.874 & 0.699 \\
LON & 0.868 & 0.767 \\
FOM & 0.886 & 0.661 \\
PER & 1.000 & 1.000 \\
\hline
\end{tabular}

Discriminant validity was assessed using the Fornell-Larcker criterion (Fornell \& Larcker, 1981). Table 4 illustrates that the Fornell-Larcker criterion (Fornell \& Larcker, 1981) is met as all the diagonal values are greater than the off-diagonal numbers in the corresponding rows and columns. Therefore, discriminant validity was established.

Table 4

Discriminant validity check

\begin{tabular}{lllllll}
\hline & AUT & COM & REL & LON & FOM & PER \\
\hline AUT & $\mathbf{0 . 7 6 9}$ & 0.490 & 0.215 & 0.311 & -0.249 & -0.034 \\
COM & 0.490 & $\mathbf{0 . 8 6 5}$ & 0.380 & 0.402 & -0.132 & 0.045 \\
REL & 0.215 & 0.380 & $\mathbf{0 . 8 3 6}$ & 0.543 & -0.067 & 0.063 \\
LON & 0.311 & 0.402 & 0.543 & $\mathbf{0 . 8 7 6}$ & -0.192 & 0.051 \\
FOM & -0.249 & -0.132 & -0.067 & -0.192 & $\mathbf{0 . 8 1 3}$ & 0.199 \\
PER & -0.034 & 0.045 & 0.063 & 0.051 & 0.199 & 1.000 \\
\hline
\end{tabular}

In sum, the psychometric properties of the measurement model were deemed to be adequate.

\subsection{Structural model}

All VIFs were below the suggested threshold of 5, thus, multicollinearity was not an issue (Kock, 2015b) and $Q^{2}$ coefficient values were greater than zero, demonstrating an acceptable level of predictive relevance (Kock, 2015b). The path estimation results are presented in Fig. 2. The hypotheses testing results (which includes path coefficients $(\beta)$ and path significance ( $p$-value)), including effect sizes $\left(f^{2}\right)$, are summarized in Table 5. $f^{2}$ values of $0.35,0.15$, and 0.02 are deemed as large, medium, and small, respectively (Cohen, 1988).

Table 5

Hypotheses testing

\begin{tabular}{cccccc}
\hline Hypothesis & Path & Path coefficient $(\beta)$ & P value & Effect size $\left(f^{2}\right)$ & Result \\
\hline H1 & COM $\rightarrow$ PER & 0.14 & $P=0.07$ & 0.01 & Not Supported \\
H2 & REL $\rightarrow$ PER & 0.08 & $P=0.20$ & 0.01 & Not Supported \\
H3 & AUT $\rightarrow$ PER & -0.23 & $P<0.01$ & 0.07 & Supported \\
H4 & LON $\rightarrow$ PER & 0.10 & $P=0.15$ & 0.02 & Not Supported
\end{tabular}




\begin{tabular}{cccccl} 
H5 & FOM $\rightarrow$ PER & 0.20 & $P=0.02$ & 0.05 & Supported \\
H6 & AUT $\rightarrow$ LON & 0.19 & $P=0.03$ & 0.07 & Not Supported \\
H7 & AUT $\rightarrow$ FOM & -0.26 & $P<0.01$ & 0.09 & Not Supported \\
H8 & COM $\rightarrow$ LON & 0.16 & $P=0.04$ & 0.07 & Not Supported \\
H9 & COM $\rightarrow$ FOM & -0.17 & $P=0.03$ & 0.05 & Not Supported \\
H10 & REL $\rightarrow$ LON & 0.45 & $P<0.01$ & 0.25 & Supported \\
H11 & REL $\rightarrow$ FOM & -0.09 & $P=0.19$ & 0.02 & Not Supported \\
\hline
\end{tabular}

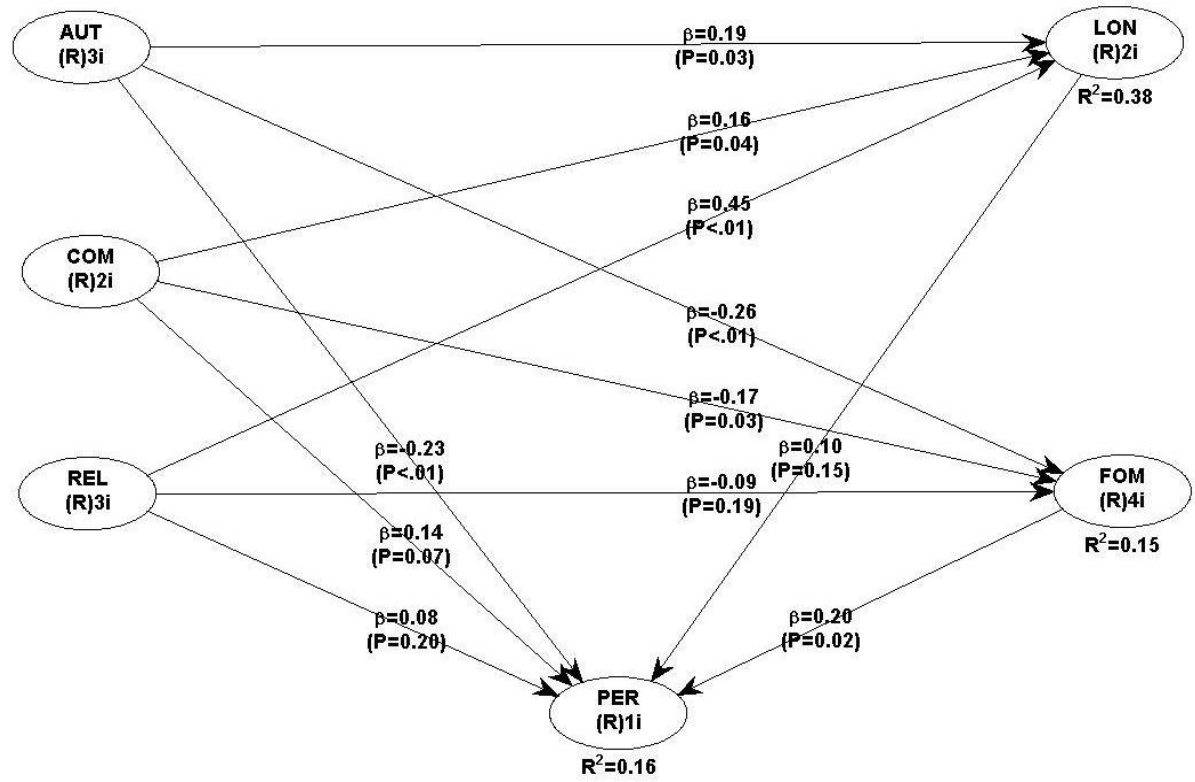

Fig. 2. PLS results

\section{Discussion}

The results reveal a number of interesting relationships, including the moderate negative relationships between Autonomy and FOMO and Autonomy and Academic Performance, and the small positive relationship between perceived Autonomy and Loneliness. Despite the moderate negative relationships between perceived Autonomy and FOMO, and perceived Competence and FOMO, there exists a moderate positive influence of FOMO on Academic Performance. The singular strong positive relationship between perceived Need for Relatedness and Loneliness, and the unexpected absence of relationships between Need for Relatedness and FOMO, on the one hand, and Academic Performance, on the other, also bear mentioning.

It can be argued that there's an aspect of conformity that manifests in FOMO on the one hand as a heightened need for relatedness, or a desire to belong, and concomitant desire to please. Correspondingly, an openness to experience might drive a need for autonomy on the other. Both needs appear to influence academic performance but in contrasting directions. Individuals high in need for autonomy perform less well 
academically, as they are likely less performance oriented and likely more prone to be intrinsically motivated academically. Whereas individuals high in FOMO perform better academically, possibly due to a need for social acceptance, manifesting as a higher need for compliance. Thus, Autonomy and FOMO may be opposed in terms of motives for social acceptance or individual agency.

A higher Need for Relatedness is related to heightened feelings of Loneliness as a higher need for relatedness possibly renders one prone to feelings of loneliness if this need is not satisfied. Yet both Need for Autonomy and Competence are related to Loneliness as well (albeit not as hypothesized), possibly as the needs involve trade-offs, in terms of the dedication of time and resources to achieving either autonomy or competence over social connection. In fact, this triadic relationship follows from Ryan and Deci's (2000) organismic integration theory, where loneliness is understood as resulting from a deficiency in needs satisfaction. Individuals that report higher needs for relatedness, autonomy, and competence are likely to report greater feelings of loneliness when these needs are not being satisfied, especially given that greater motivational integration (i.e., proceeding from extrinsic sources to intrinsic motivation) is supported by environments higher in relatedness (Ryan \& Deci, 2000).

The negative influence of Autonomy on Academic Performance can be attributable respectively to different learning profiles such as the Surface, and Deep Learning and Achievement orientations (Biggs, 1993; Biggs, Kember, \& Leung, 2001), that is, whether students seek either understanding or academic performance differentially influences learning orientations and study strategies. The variety of learning orientations explains the attenuated relationship between Need for Competence and Academic Performance, as well as the absence of relationship between Need for Relatedness and Academic Performance, the relationship between FOMO and academic performance, and the negative relationship between Autonomy and Academic Performance as artifacts of different academic motivation profiles (Litalien et al., 2017; Vallerand, 1997; Vallerand et al., 1992). Motivation for learning is situationally determined (Baeten, et al., 2010; Litalien et al., 2017; Guay, Vallerand, \& Blanchard, 2000) and intrinsic motivation is the only consistent motivational predictor of academic achievement (Taylor et al., 2014), hence, adaptive integrative behaviors will be supported to the degree that students' basic needs are satisfied.

\subsection{Limitations}

This study is limited by its use of a convenience sample and self-reports, and its crosssectional nature. Furthermore, we did not explicitly situate our study in the context of social media use. However, the problematic relationship between anxiety, depression, and loneliness and social media use has been well established and FOMO is a social media phenomenon. We do not dispute the reality. Rather, we opted to examine the link more generally as these comorbid psychopathologies are related to a variety of instances of problematic uses and behaviors, social media use notwithstanding.

\subsection{Future directions}

Future studies might use mixed-measures, longitudinal time and experience sampling, to understand how an individuals' motivations influence the experience of loneliness and FOMO, to understand the dynamical influences on students' academic performance throughout their academic program. As the study of internal motivations can also help to understand how the social context affords and constrains the expression of intrinsic 
motivation (Ryan \& Deci, 2000) encouraging the satisfaction of students' basic needs for autonomy, competence, and relatedness might proactively address the epidemic of loneliness and FOMO among college-age students.

\section{ORCID}

David John Lemay (iD https://orcid.org/0000-0003-2000-524X

Tenzin Doleck (iD https://orcid.org/0000-0002-1279-689X

\section{References}

Ahn, J. (2011). The effect of social network sites on adolescents' social and academic development: Current theories and controversies. Journal of the American Society for Information Science and Technology, 62(8), 1435-1445.

Alt, D. (2015). College students' academic motivation, media engagement and fear of missing out. Computers in Human Behavior, 49, 111-119.

Baeten, M., Kyndt, E., Struyven, K., \& Dochy, F. (2010). Using student-centred learning environments to stimulate deep approaches to learning: Factors encouraging or discouraging their effectiveness. Educational Research Review, 5(3), 243-260.

Barnett, T., Pearson, A. W., Pearson, R., \& Kellermanns, F. W. (2015). Five-factor model personality traits as predictors of perceived and actual usage of technology. European Journal of Information Systems 24(4), 374-390.

Bazelais, P., Doleck, T., \& Lemay, D. J. (2017). Exploring the association between formative and summative assessment in a pre-university science program. Journal of Formative Design in Learning, 1(2), 65-72. doi:10.1007/s41686-017-0012-2

Bazelais, P., Lemay, D. J., \& Doleck, T. (2016). How does grit impact students' academic achievement in science? European Journal of Science and Mathematics Education, 4(1), 33-43.

Bazelais, P., Lemay, D. J., \& Doleck, T. (2018). Examining the link between prior achievement in secondary education and performance in college: Using data from preuniversity physics courses. Journal of Formative Design in Learning, 2(2), 114-120. doi:10.1007/s41686-018-0020-x

Bazelais, P., Lemay, D. J., \& Doleck, T. (2019). Exploring the role of testing in student outcomes: Evidence from a mechanics course. International Journal of Engineering Education, 35(4), 1170-1175.

Biggs, J., Kember, D., \& Leung, D. Y. P. (2001). The revised two-factor study process questionnaire: R-SPQ-2F. British Journal of Educational Psychology, 71(1), 133-149.

Biggs, J. B. (1993). From theory to practice: A cognitive systems approach. Higher Education Research \& Development, 12(1), 73-85.

Błachnio, A., \& Przepiórka, A. (2018). Facebook intrusion, fear of missing out, narcissism, and life satisfaction: A cross-sectional study. Psychiatry Research, 259, 514-519.

Blackwell, D., Leaman, C., Tramposch, R., Osborne, C., \& Liss, M. (2017). Extraversion, neuroticism, attachment style and fear of missing out as predictors of social media use and addiction. Personality and Individual Differences, 116, 69-72.

Bosau, C., \& Aelker, L. (2015). Who is affected by FoMO (Fear of Missing Out)? Measuring a new phenomenon in the digital era. Paper presented at the 13th European Conference on Psychological Assessment (ECPA). Zurich.

Cohen, J. (1988). Statistical power analysis for the behavioral sciences (2nd ed.). 
Hillsdale, NJ: Lawrence Erlbaum Associates.

CREPUQ. (2007). The $R$ score: What it is, and what it does. Retrieved from http://collections.banq.qc.ca/ark:/52327/bs1865123

Deci, E. L., \& Ryan, R. M. (1985). Intrinsic motivation and self-determination in human behaviour. New York, NY: Plenum.

Elhai, J. D., Dvorak, R. D., Levine, J. C., \& Hall, B. J. (2017). Problematic smartphone use: A conceptual overview and systematic review of relations with anxiety and depression psychopathology. Journal of Affective Disorders, 207, 251-259.

Elhai, J. D., Levine, J. C., Dvorak, R. D., \& Hall, B. J. (2017). Non-social features of smartphone use are most related to depression, anxiety and problematic smartphone use. Computers in Human Behavior, 69, 75-82.

Eltantawy, N., \& Wiest, J. (2011). Social media in the Egyptian revolution: Reconsidering resource mobilization theory. International Journal of Communication, 5, 1207-1224.

Fornell, C., \& Larcker, D. F. (1981). Evaluating structural equation models with unobservable variables and measurement error. Journal of Marketing Research, 18(1), 39-50.

Goodman-Deane, J., Mieczakowski, A., Johnson, D., Goldhaber, T., \& Clarkson, P. J. (2016). The impact of communication technologies on life and relationship satisfaction. Computers in Human Behavior, 57, 219-229.

Guay, F., Vallerand, R. J., \& Blanchard, C. (2000). On the assessment of situational intrinsic and extrinsic motivation: The situational motivation scale (SIMS). Motivation and Emotion, 24(3), 175-213.

Henseler, J., Hubona, G., \& Ray, P. A. (2016). Using PLS path modeling in new technology research: Updated guidelines. Industrial Management \& Data Systems, 116(1), 2-20. doi: 10.1108/imds-09-2015-0382

Jenkins-Guarnieri, M. A., Vaughan, A. L., \& Wright, S. L. (2015). Development of a self-determination measure for college students. Measurement and Evaluation in Counseling and Development, 48(4), 266-284.

King, R. B. (2015). Sense of relatedness boosts engagement, achievement, and wellbeing: A latent growth model study. Contemporary Educational Psychology, 42, 2638.

Kock, N. (2015a). WarpPLS. Retrieved from http://www.warppls.com

Kock, N. (2015b). WarpPLS 5.0 user manual. ScripWarp Systems. Retrieved from http://cits.tamiu.edu/WarpPLS/UserManual_v_5_0.pdf

Krasnova, H., Widjaja, T., Buxmann, P., Wenninger, H., \& Benbasat, I. (2015). Why following friends can hurt you: An exploratory investigation of the effects of envy on social networking sites among college-age users. Information Systems Research 26(3), $585-605$.

Lim, M. (2012). Clicks, cabs, and coffee houses: Social media and oppositional movements in Egypt, 2004-2011. Journal of Communication, 62(2), 231-248.

Litalien, D., Morin, A. J. S., Gagné, M., Vallerand, R. J., Losier, G. F., \& Ryan, R. M. (2017). Evidence of a continuum structure of academic self-determination: A twostudy test using a bifactor-ESEM representation of academic motivation. Contemporary Educational Psychology, 51, 67-82.

Mahoney, J., Le Moignan, E., Long, K., Wilson, M., Barnett, J., Vines, J., \& Lawson, S. (2019). Feeling alone among 317 million others: Disclosures of loneliness on Twitter. Computers in Human Behavior, 98, 20-30.

McPherson, M., Smith-Lovin, L., \& Brashears, M. E. (2006). Social isolation in America: Changes in core discussion networks over two decades. American Sociological Review, 71(3), 353-375. 
Oberst, U., Wegmann, E., Stodt, B., Brand, M., \& Chamarro, A. (2017). Negative consequences from heavy social networking in adolescents: The mediating role of fear of missing out. Journal of Adolescence, 55, 51-60.

Pittman, M., \& Reich, B. (2016). Social media and loneliness: Why an Instagram picture may be worth more than a thousand Twitter words. Computers in Human Behavior, $62,155-167$.

Przybylski, A. K., Murayama, K., DeHaan, C. R., \& Gladwell, V. (2013). Motivational, emotional, and behavioral correlates of fear of missing out. Computers in Human Behavior, 29(4), 1841-1848.

Russell, D., Peplau, L. A., \& Cutrona, C. E. (1980). The revised UCLA loneliness scale: Concurrent and discriminant validity evidence. Journal of Personality and Social Psychology, 39(3), 472-480.

Ryan, R. M., \& Deci, E. L. (2000). Intrinsic and extrinsic motivations: Classic definitions and new directions. Contemporary Educational Psychology, 25(1), 54-67.

Scott, H., \& Woods, H. C. (2018). Fear of missing out and sleep: Cognitive behavioural factors in adolescents' nighttime social media use. Journal of Adolescence, 68, 61-65.

Sheldon, P., \& Bryant, K. (2016). Instagram: Motives for its use and relationship to narcissism and contextual age. Computers in Human Behavior 58, 89-97.

Stead, H., \& Bibby, P. A. (2017). Personality, fear of missing out and problematic internet use and their relationship to subjective well-being. Computers in Human Behavior, 76, 534-540.

Taylor, G., Jungert, T., Mageau, G. A., Schattke, K., Dedic, H., Rosenfield, S., \& Koestner, R. (2014). A self-determination theory approach to predicting school achievement over time: The unique role of intrinsic motivation. Contemporary Educational Psychology, 39(4), 342-358.

Turkle, S. (2011). Alone together: Why we expect more from technology and less from each other. New York, NY: Basic Books.

Vallerand, R. J. (1997). Toward a hierarchical model of intrinsic and extrinsic motivation. Advances in Experimental Social Psychology, 29, 271-360.

Vallerand, R. J., Fortier, M. S., \& Guay, F. (1997). Self-determination and persistence in a real-life setting: Toward a motivational model of high school dropout. Journal of Personality and Social Psychology, 72(5), 1161-1176.

Vallerand, R. J., Pelletier, L. G., Blais, M. R., Briere, N. M., Senecal, C., \& Vallieres, E. F. (1992). The academic motivation scale: A measure of intrinsic, extrinsic, and amotivation in education. Educational and Psychological Measurement, 52(4), 10031017.

Vansteenkiste, M., Sierens, E., Soenens, B., Luyckx, K., \& Lens, W. (2009). Motivational profiles from a self-determination perspective: The quality of motivation matters. Journal of Educational Psychology, 101(3), 671-688.

Wegmann, E., Oberst, U., Stodt, B., \& Brand, M. (2017). Online-specific fear of missing out and Internet-use expectancies contribute to symptoms of Internet-communication disorder. Addictive Behaviors Reports, 5, 33-42.

Wolf, E. J., Harrington, K. M., Clark, S. L., \& Miller, M. W. (2013). Sample size requirements for structural equation models. Educational and Psychological Measurement, 73(6), 913-934. 